\title{
Del apocalipsis al galicinio de la traición. El gallo como motivo simbólico en dos cuentos de José Jiménez Lozano
}

\author{
From the Apocalypse to the Crowing of Betrayal. \\ The Rooster as a Symbolic Motif in Two Tales \\ by José Jiménez Lozano
}

\author{
Alicia Nila Martínez Díaz \\ Universidad Villanueva \\ anila@villanueva.ed \\ ORCID iD: https://orcid.org/0000-0002-5909-4342
}

\section{RESUMEN}

El artículo analiza la presencia del gallo como motivo simbólico y sus posibles significados en los cuentos «El ángel del Juicio» y «El Benefactor», de José Jiménez Lozano. Para acometer este estudio se han examinado las diversas simbologías que esta icónica ave ha adquirido a lo largo de los tiempos y se han puesto en relación con las diferentes significaciones que ostenta el animal en cada historia. En conclusión, el análisis de los relatos constata que, gracias a la polisemia simbólica que esta ave acoge bajo sus alas, el gallo actúa como un motivo simbólico muy potente y que es utilizado por el autor para conceptualizar problemáticas complejas, tales como el miedo a la muerte o el inexorable paso del tiempo, al tiempo que se corrobora la polisemia simbólica de esta ave.

Palabras Clave: José Jiménez Lozano; literatura española; cuento; gallo; simbolismo.

\begin{abstract}
The article analyzes the presence of the rooster as a symbolic motive and its possible meanings in the stories "The angel of Judgment" and "The Benefactor", by José Jiménez Lozano. To undertake this study, we have examined the various symbologies that this iconic bird has acquired over the years and have been related to the different meanings that the animal has in each story. In conclusion, the analysis of the stories confirms that, thanks to the symbolic polysemy that this bird receives under its wings, the rooster acts as a very powerful symbolic motive and is used by the author to conceptualize complex problems, such as the fear of death or the inexorable passage of time, at the same time, that the symbolic polysemy of this bird is corroborated.
\end{abstract}

Key words: José Jiménez Lozano; Spanish Literature; Tale; Rooster; Symbolism. 
«El símbolo puede decirle al hombre, como la esfinge de Emerson:

De tu ojo soy la pupila»

Charles S. Peirce

Pudiera parecer que sobre el gallo y sus muchos significados todo se ha dicho ya. Arquetipo de ave radiante por excelencia, se supone que los griegos adoptaron este animal, oriundo de Persia, tras las guerras médicas (Castro y García 1997, 29). A partir de entonces, su expansión por Occidente fue meteórica, de manera que no extraña encontrar huellas de su presencia en mitos y leyendas de tradiciones culturales muy diversas. Japón, Grecia, Roma... En muchas de las antiguas civilizaciones el gallo ha ocupado un lugar significativo, cobrando una importancia capital tanto en las tradiciones populares como en los sistemas religiosos.

En la India es el atributo del dios Skanda, personificación de la energía solar. En el Japón su canto está asociado a Amaterasu, diosa del Sol, a quien hizo salir de la caverna en que se escondía y según las tradiciones helénicas era un atributo particular de Apolo, el héroe del día que nace. En el islam goza de una veneración absoluta y con su canto se señala la presencia del ángel (Chevalier y Gheerbrant 1986, 520-522).

Desde entonces, el gallo ha recorrido un largo camino, durante el que no ha perdido ni una pluma de su lozanía y vigor simbólicos. Tres se consideran los rasgos definitorios de este polisémico animal: insignia de potencia sexual, combatividad y capacidad para anunciar la llegada del día. De ellos se derivan buena parte de las creencias y significados que se le han ido otorgando paulatinamente a lo largo de los siglos, ya que se trata de un animal que siempre ha estado marcado por unas fuertes connotaciones simbólicas. Posteriormente, su inserción en el bestiario de la Iglesia católica añadió nuevos significados a los preexistentes, al hacer de esta ave «emblema directo de Cristo, el padre, el jefe, el guía» (Charbonneau-Lassay 1997, 633).

Probablemente sea uno de los pocos integrantes del mundo animal que pueda jactarse no solo de mantener intacta, sino de aumentar, incluso, su pléyade de significaciones. Buena parte de ello quizá se deba a su profunda naturaleza mística. El gallo es un ave dotada de una naturaleza escindida. Heraldo de la luz y representación de la resurrección, también ha sido considerado a lo largo de los tiempos como un símbolo de las tinieblas. George Steiner apunta que en las creencias de Oriente Próximo y en ciertas ramas de la mitología clásica y céltica, si el gallo es «negro está presente en los ritos funerarios y forma parte del bestiario del mundo subterráneo» $(2001,434)$.

De modo que junto a su faceta uránica y solar posee este animal otra vinculada a la oscuridad y al reino de los muertos ${ }^{1}$. Imagen ambivalente, por

${ }^{1}$ El panteón grecolatino es aquel que mejor ha representado la dualidad de esta figura animal. Además de estar vinculado a Hermes, mensajero de los dioses y dios de los caminos, 
tanto, y que ofrece una amplia panoplia de significaciones, tal y como el arte y la literatura se han encargado de señalar y representar ${ }^{2}$. Shakespeare recogió magistralmente el anverso y reverso de este símbolo complejo y palpitante:

It faded on the crowing of the cock.

Some say that ever 'gainst that season comes

Wherein our Saviour's birth is celebrated,

The bird of dawning singeth all night long;

And then, they say, no spirit dare stir abroad,

The nights are wholesome, then no planets strike,

No fairy takes, nor witch hath power to charm;

So hallowed and so gracious is that time $(2006,108)$.

Los fantasmas desaparecen y ni hadas ni brujas osan vagar por la tierra. El ave mañanera conjura con su canto los poderes de la oscuridad. Canta ininterrumpidamente la noche del nacimiento de Cristo pero, a la vez, convoca la tiniebla funesta de la muerte. Ciertamente, es un animal desconcertante, utilizado a lo largo de la historia para representar realidades antitéticas.

Sin embargo, esta fusión de opuestos en el seno simbólico del gallo tampoco ha de extrañar, pues resulta ser una cualidad bastante común de los símbolos. Esta es una de las conclusiones más complejas que alcanza Carl Gustav Jung $(2002,474)$ en su obra Misterium Coniunctionis. Desde su punto de vista, la conciliación de opuestos requiere siempre de una actuación simbólica.

el gallo representa también a Asclepio, dios de la medicina y artífice de varias resucitaciones, motivo por el cual este dios, y el gallo en su defecto, se asocian a la constelación de Deméter y Dionisio, vinculada a los ciclos naturales de muerte y resurrección.

2 Por citar otros dos ejemplos de la larga lista de autores que han incluido al gallo en sus creaciones mencionaremos a Geoffrey Chaucer. Entre sus Canterbury Tales se encuentra The Nun's Priest's Tale, cuyo protagonista es el afamado gallo Chauntecleer, heraldo de la aurora. $\mathrm{Su}$ desgraciado final, como los de los gallos que estudiaremos, le fue vaticinado en un sueño premonitorio. http://academic.brooklyn.cuny.edu/webcore/murphy/canterbury/17nunpriest.pdf

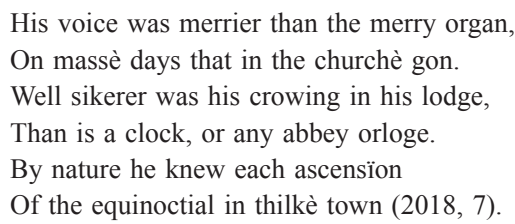

En contraposición, un buen ejemplo de la naturaleza tenebrosa del ave la encontramos en El satiricón, de Petronio. En esta obra, el gallo es el bucinator, clarín de la muerte: cuanto estaba diciendo esto cantó el gallo. Desconcertado por el canto, Trimalción mandó derramar vino debajo de la mesa y rociar también la lámpara de vino puro. Y es más, se cambió el anillo a la mano derecha diciendo: «No en balde ese clarín ha dado una señal. Lo normal es que se produzca un incendio o que algún vecino vaya a morir. Dios nos proteja. De modo que aquél que me traiga al mensajero recibirá una propina» $(1996,66)$. 
Para sintetizar dos aspectos de lo real mutuamente excluyentes se necesita un fuerte proceso energético que desemboca en un símbolo. Es decir, todo símbolo contiene siempre en su núcleo este «misterium coniunctionis», esta coincidencia de contrarios unidos por la representación o el «Lógos», siendo de aquí de donde parte la amplitud semántica de los símbolos. Como se mostrará a lo largo del presente trabajo, esta bipolaridad, tan propia de los símbolos, se haya presente en el simbolismo del gallo cuando, en un primer momento, aparece como heraldo de la muerte, pero después es asimilado al apocalíptico ángel de la trompeta, anunciador de la vida eterna.

A partir de estos presupuestos, el presente trabajo se propone analizar los significados que adquiere este animal en los cuentos «El ángel del Juicio»y «El Benefactor», escritos por José Jiménez Lozano (Langa, 1930). Este Premio Cervantes se sirve de la ambivalencia simbólica del ave para componer dos historias, dispares entre sí, pero hermanadas por un único motivo: el gallo y su canto. Relatos en los que se dirimen temáticas universales como la vida y su fragilidad, el miedo a la muerte y el final de los tiempos; también el valor de la infancia, el paso del tiempo o la belleza malograda de los sueños rotos son, entre otros, temas que el escritor abulense aglutinará en torno al motivo del gallo.

\section{De ANimales y hombres en la nARRATiva de José JimÉnez LoZANo}

La presencia de los animales en la obra de José Jiménez Lozano es innegable. En sus novelas, cuentos y poemas abundan los elementos procedentes del mundo animal. Tres de sus novelas llevan por título nombres de animales: La salamandra (1973), Los lobeznos (2001) y Las gallinas del licenciado $(2005)^{3}$. También son numerosos los cuentos cuyo motivo referencial son los animales: «Los cuquillos», «El gorrioncillo» «Las garzas», «El cordero», «La rana», «El gusano», «Historia de un perro», «La guerra de los grillos», «La burra de Balaam» o «Cuello de garza». Magníficos relatos y muestra del importante papel que ostentan los animales en el imaginario jimenezlozaniano ${ }^{4}$.

A través de los títulos citados se colige que en la narrativa de este escritor los animales constituyen una constante digna de consideración, así como el

${ }^{3}$ A lo largo de su dilatada trayectoria literaria, José Jiménez Lozano ha publicado veintisiete novelas, trece colecciones de cuentos, diez dietarios, veintiún ensayos, cinco compilaciones de artículos periodísticos y nueve poemarios. Para una perspectiva completa de su obra, véase la página web oficial del escritor: http://www.jimenezlozano.com/v_portal/ apartados/apartado.html.

${ }^{4}$ Los títulos señalados se encuentran diseminados en las diferentes colecciones de cuentos publicados por José Jiménez Lozano. Los títulos de los volúmenes a los que remitimos son: El grano de maíz rojo (1988), El santo de mayo (1989), Antología de cuentos (2005), La piel de los tomates (2007), El azul sobrante (2009) y La querencia de los búhos (2019). 
hecho de que la variedad de las especies utilizadas por Jiménez Lozano en sus historias es muy amplia. Y aunque el autor niegue que posean carga metafórica alguna, «esos bichos míos no tienen significación moral, ni alegórica, ni simbólica» (Arbona 2008, 358), el valor de algunos de ellos se repite, llegando a adquirir a veces un profundo significado simbólico.

Por motivos de extensión, de entre todos los títulos existente nos limitaremos a seleccionar aquellos en los que el simbolismo de los animales representados no solo queda patente, sino que, además, dichos animales ocupan un lugar preeminente en la estructura narrativa de la obra en la que aparecen. Sería este el caso de la salamandra y los lobeznos, animales que, en las novelas homónimas, representarían la humillación y la animalización del ser humano, respectivamente; mientras que el cordero del cuento mencionado sería la mansedumbre a la hora de la asunción del sacrificio, por citar, como decimos, algunos de los títulos señalados. En la mayor parte de las ocasiones, los animales se encuentran vinculados al personaje y a través de ellos se describe un «elemento simbólico de su naturaleza o un rasgo ontológico de esa criatura de ficción» (Arbona 2008, 359).

Un buen ejemplo de esta aseveración la encontramos en el cuento de «Los cuquillos», donde se narra la desventura de una joven preñada por el hijo del hombre más rico del pueblo. El padre de la muchacha expresa al abogado su deseo de retirar la denuncia contra el agresor, pues, al fin y al cabo, los pobres siempre han sido pobres o, como dice su mujer «la Ignacia: que hay que nacer, y nosotros hemos nacido para nada. Todos castrados teníamos que estar los pobres y ya se habría acabado la raza» (Jiménez 2005a, 138). El título del cuento se debe al apodo con que se conoce a la familia protagonista en el pueblo. Ellos, a pesar de haber nacido para dedicarse a cantar, no pueden hacerlo al carecer de medios económicos: «esta familia de cuquillos, como nos llaman, no cantaría más en este mundo» (Jiménez 2005a, 138).

Sin embargo, además de esta circunstancia, existen otros textos en los que los animales desempeñan una función estructural dentro de la trama, convirtiéndose en el motivo principal de los mismos. El gusano es un buen ejemplo de ello. Texto breve y sobrecogedor, en el que un médico insta al César a ajusticiar a todos los cristianos. Los considera una plaga, que se extenderá por todo el Imperio y conducirá, irremediablemente, a su caída. Su petición está motivada por la visión dentro del santo sepulcro de un gusano sobre el pecho del cadáver de Jesús. En esta ocasión, el animal no mantiene un vínculo directo con ninguno de los personajes del relato, sino que se erige en el símbolo principal de la historia al ser la encarnación del Espíritu Santo.

Por otra parte, conviene señalar que dentro de la amplia obra del autor abulense se encuentra una gran variedad de cuentos, novelas y poemas en donde las aves aparecen como motivo central. Habida cuenta de la especial predilección que el autor siente por las mismas, no podía ser de otra manera. Jiménez Lozano ha manifestado en más de una ocasión que los pájaros le re- 
sultan «particularmente queridos y respetados» (Arbona 2011, 49) y cuando se le pregunta el porqué, responde que mantienen «amistad desde hace muchos años, tienen los ojos redondos y vuelan, no pesan apenas; parecen ángeles de compañía, o son seres dulces o burlones como el cuco, pobrecillos como los gorriones, elegantes como los cuervos y los estorninos, etc.» (Arbona 2011, 49). Tanto es así, que su último volumen de cuentos - publicado en marzo de 2019- lleva por título «La querencia de los búhos», un ejemplo más de esta «querencia» suya por las aves.

Como prueba de ello, baste la mención de los títulos «La amenaza del estratego» y «El jubilado». En el primer relato, protagonizado enteramente por distintos tipos de aves, estas desempeñan diferentes oficios en concordancia con sus características físicas, sus hábitos o sus comportamientos. Así, encontramos a la Hermana Gallina, responsable de las convocaciones y reuniones capitulares, al Pato como cocinero, al Loro como intérprete de las seis lenguas antiguas, al Búho que es el vigilante nocturno y procurador de los sueños, al Pájaro carpintero como ebanista, al Correcaminos que es el agrimensor o al «Hermano Petirrojo, observador de los setos y murallas del mundo» (Jiménez 2004, 77), entre otros. Con estos personajes, Jiménez Lozano relata la historia de un monasterio cuyos monjes deciden abandonar la mansedumbre evangélica e ir a la guerra contra el Tirano llamado El Ecologista, a petición del emperador de Constantinopla ${ }^{5}$. En el caso del segundo cuento, encontramos que la parroquia del protagonista se convierte en una granja de cría de aves ${ }^{6}$.

En el estudio que sigue, el animal determinante será el gallo. La elección de este animal de entre todos los presentes en la obra del castellano, así como de los relatos seleccionados ha sido parcialmente respondida hasta ahora. El hecho de encontrar la misma ave inserta en dos cuentos tan dispares entre sí, pero concomitantes en su motivo principal, resulta acicate suficiente para una investigación pormenorizada del fenómeno. Asimismo, la selección de títulos se debe a que las dos circunstancias arriba mencionadas se hayan presentes en los relatos. Por un lado, el gallo posibilita que se desvele un rasgo ontológico del personaje protagonista, tal es lo sucede en el cuento de «El Benefactor», y por otro, encontramos al gallo como motivo principal del relato en el título de «El ángel del Juicio». En última instancia, el estudio de un ave tan polisémica

${ }^{5}$ Además del género narrativo, si nos circunscribimos a la producción poética de José Jiménez Lozano existe un estudio pormenorizado sobre la presencia de las aves en su poesía de S. Stuart Park (2009). El vídeo de la presentación del libro en el que intervienen el autor y José Jiménez Lozano está disponible en la siguiente dirección: https://www.youtube. $\mathrm{com} /$ watch?v=H6PraexkDQA

${ }^{6}$ Queda claro que son muchas y variadas las obras que en la bibliografía del autor tienen como tema central a las aves, aunque por motivos de extensión no resulte posible mencionar todas y cada una de ellas. 
como el gallo constituye por sí sola una excelente razón para la realización del presente trabajo.

Su consideración como motivo simbólico en este trabajo requiere de una aproximación previa a estos términos, así como una justificación acerca de porqué se considera al gallo como tal en los relatos seleccionados. En lo que se refiere al término de «motivo», tomamos las palabras de Tomachevski como guía cuando define el «motivo» como «una unidad temática que se repite en diversas obras (por ejemplo, "el rapto de la novia", "los animales colaboradores", es decir, los animales que ayudan al protagonista a resolver sus propios trabajos, etc.). Estos motivos pasan enteramente de una estructura narrativa a otra» $(1982,186)$.

En el caso que nos ocupa, el gallo resulta ser una unidad temática con entidad propia, pues, como señala el formalista ruso, la figura del ave condensa todo el espesor temático de los cuentos analizados. Como leitmotiv de ambas narraciones, el ave del amanecer apunta directamente al plano central del argumento y lo hace actuando como aglutinante, como elemento vertebrador de la diégesis ficcional, por lo que el resto de los elementos de la gramática narrativa van a organizarse en torno a él. En este mismo sentido cabe añadir, siguiendo de nuevo a Tomachevski, que el gallo puede considerarse un «motivo dinámico» ${ }^{7}(1982,188)$, debido a que su presencia o aparición modifica las situaciones de partida en cada una de las historias en que se imbrica.

Su papel es determinante en el cuento de «El Benefactor», pues su aparición constituye el plot point definitivo que conduce al sorprendente final de la historia. En «El ángel del Juicio» el gallo, en cambio, es el detonante que suscita la conversación entre las comadres que resulta ser objeto del discurso narrativo $\mathrm{y}$ en la que se somete al ave a un profundo proceso de resemantización.

Llevemos ahora a cabo un acercamiento al término de «símbolo». Acercamiento cauteloso, eso sí, puesto que esta figura retórica es, probablemente, el recurso estilístico más complejo, polémico y difícil que existe. Marchesse y Forradellas apuntan que se trata de «un término extremadamente polisémico, tanto si lo consideramos en las diferentes ramas del saber humano en que se emplea (por ejemplo, la lógica simbólica), como si lo referimos únicamente a las que se relacionan directamente con la simbología, la lingüística o la literatura» $(2013,381)^{8}$.

${ }^{7}$ Afirma Tomachevski que «los motivos se califican según su objetivo contenido de acción. Los motivos que modifican la acción son dinámicos, mientras que los que no la modifican son estáticos [...] Los motivos dinámicos son los motores principales de la fábula, mientras en la organización de la trama pueden, a veces, exaltarse los motivos estáticos» $(1982,188)$.

${ }^{8}$ Tras confrontar las definiciones de símbolos propuestas por Peirce y Saussure, Marchesse y Forradellas convienen en que «queda viva la naturaleza sígnica del símbolo, pero se le añaden determinaciones complementarias que remiten al carácter plurisotópico del 
La definición en sí misma resulta, cuanto menos, resbaladiza, y por ello encontramos autores que consideran al símbolo como un signo. Tal es el caso de Estébanez Calderón y de Helena Beristaráin ${ }^{9}$. Sin embargo, desde nuestro punto de vista resulta más acertada para nuestro trabajo la aportación de Ducrot y Todorov, quienes oponen «signo» y «símbolo», al encontrar diferencias fundamentales entre ambos. Para ellos, mientras que en el signo

la significación y el significado mantienen una relación inmotivada [...] y a la vez necesaria» (significante y significado se necesitan mutuamente en el signo), en el símbolo, por el contrario, «simbolizante y simbolizado presentan una relación motivada [...] y no necesaria (o «arbitraria») porque el simbolizante el «simbolizante» y a veces el «simbolizado» (los significados llama y deseo) existen independientemente el uno del otro; precisamente por esta razón, la relación no puede ser sino motivada: en otros términos, nada obligaría a establecerla» $(1974,124)$.

El ejemplo de la balanza resulta más que ilustrativo. Como símbolo, la balanza representa la justicia, la distribución equitativa de los pesos, pero al mismo tiempo, la balanza tiene existencia autónoma por sí misma, despojada de su significado simbólico, de ahí la relación «no necesaria» que Ducrot y Todorov mencionan.

Situación análoga a la planteada por estos autores la encontramos cuando consideramos al gallo como un símbolo en los cuentos seleccionados. ¿Qué sucede con el animal en sus páginas? En ambos títulos, al gallo se lo considera primeramente como una entidad animal. El ave en «El ángel del Juicio» altera el equilibrio de la pequeña comunidad en que habita su dueña con su hábito de cantar sobre las tumbas de los recién fallecidos y en «El Benefactor», su mera aparición resulta fatal y definitiva para resolver el destino del protagonista.

discurso y valor connotativo de sus elementos constituyentes» $(2013,381)$ y consideran que existen símbolos que alcanzan a toda la humanidad, mientras que otros están ligados a determinadas épocas o formas culturales.

${ }^{9}$ Helena Beristáin, por su parte, coincide en su consideración del símbolo como signo al definirlo como «un signo que, en la relación signo-objeto, se refiere al objeto que denota en virtud de una ley o convención que es su condición constitutiva y que suele consistir en una asociación de ideas generales que determina la interpretación del símbolo por referencia al objeto» $(1995,458)$ y destaca que «su carácter reside en el hecho de que existe la convención de que será interpretado como signo, aunque nada establezca la conexión entre signo y objeto» $(1995,458)$. Estébanez Calderón en su célebre Diccionario de términos literarios abre la definición de «símbolo» con las siguientes líneas: «Es un signo cuya presencia evoca otra realidad sugerida o representada por él: p. e., el olivo representa en la cultura mediterránea la idea de paz; esta misma idea sugiere la paloma en la cultura bíblica; olivo y paloma son símbolos de paz. En la Retórica clásica el símbolo es un tropo que, al igual que la metáfora, la metonimia o la alegoría consiste en la sustitución de una palabra por otra, con la correspondiente traslación de significado» $(1996,993)$. 
Ahora bien, más allá de su existencia como animal, el gallo mantiene en las dos historias relaciones arbitrarias con el resto de los elementos del discurso en los distintos niveles de la trama y además establece relaciones substanciales con los personajes que confieren vida a la narración, lo cual propicia el establecimiento de una serie relaciones motivadas que dan carta de naturaleza a la consideración del gallo como símbolo. Por decirlo con palabras de Paul Ricoeur, el gallo es «una entidad concreta que señala más allá de sí misma hacia algo completamente distinto que se manifiesta en ella» $(2006,68)$ y es que, como signo dentro del discurso, el animal contiene ese «excedente de sentido» $(2006,68)$ que el crítico francés postula como propio y exclusivo de los símbolos ${ }^{10}$.

Tal y como desvelará el análisis posterior, a través del gallo Jiménez Lozano ha conceptualizado realidades complejas, ubicadas más allá de la neta presencia del animal, dotando al gallo de un «excedente de significado» gracias al cual, el poder simbólico del gallo se fortalece y se hace patente de distintas maneras. En «El ángel del Juicio» el gallo es el eje que marca la relación entre el mundo de los vivos y de los muertos, mientras que en «El Benefactor» su canto simboliza la traición a los sueños de la infancia, al tiempo que vindica la supremacía de la memoria sobre los poderes de lo fáctico.

Por otra parte, resulta también conveniente atender a las peculiaridades de la obra en la que se enmarcan los textos seleccionados, es decir, a los rasgos más sobresalientes y caracterizadores de la producción narrativa de José Jiménez Lozano, porque lo cierto es que en ella abundan los símbolos, como hemos visto en los ejemplos anteriormente citados.

De hecho, podría decirse que buena parte de la densidad de sus historias proviene precisamente de ahí, de su habilidad para expresar mediante símbolos problemáticas muy diversas, pero que apuntan siempre a cuestiones cardinales de la naturaleza humana. Para el autor los símbolos no constituyen un mero recurso retórico, sino que, a su modo de ver, son la manera más directa, sencilla, hermosa y efectiva de nombrar ${ }^{11}$ :

${ }^{10}$ Según el crítico francés «este excedente de sentido en un símbolo puede ser opuesto a la significación literal, pero solo con la condición de que también opongamos dos interpretaciones al mismo tiempo. Solo para una interpretación hay dos niveles significación, ya que es el reconocimiento del sentido literal lo que nos permite ver que un símbolo todavía contiene más sentido. Este excedente de sentido es el residuo de la interpretación literal» (Ricoeur 2006, 68).

${ }^{11}$ Escapa a los límites de este estudio, pero resultaría muy interesante un trabajo en el que se estudiara en profundidad los principales símbolos que aparecen y se reiteran en diferentes obras de José Jiménez Lozano. A este respecto, en la tesis doctoral de Ana María Martínez, El imaginario antropológico de Maestro Huidobro de José Jiménez Lozano, se lleva a cabo un magnífico análisis de los principales símbolos de la novela y de sus significados. Para una mayor profundización en esta cuestión, véase Martínez 2019. 
El símbolo no me parece a mí un recurso, sino la única posibilidad de nombrar en lo profundo y sin la concreción, y, por lo tanto, sin los límites bien definidos de un nombrar geométrico y racional. Por ejemplo, si yo digo que estoy en un pozo o en una noche, aquella persona a las que se lo digo queda infinitamente más al tanto de mi situación que si digo que ésta es muy triste y no veo posibilidad de salir de ella. Ese símbolo del pozo y de la noche golpea con seguridad su ánima, mientras que mi explicación racional es una información destinada al intelecto (Arbona 2016, 29).

Para José Jiménez Lozano, los símbolos son una parte esencial de esa «lengua carnal y verdadera» $(2003,86)$ con la que escribe sus historias, porque el símbolo proporciona al autor un medio idóneo con el que captar y traducir esas ásperas circunstancias que marcan sus narraciones y con las que arrasa el corazón de los lectores.

\section{EL PODER DEL AUGURIO}

«El ángel del Juicio», incluido en el volumen El grano de maíz rojo (1988), adquiere la forma de una conversación entre dos vecinas acerca de sus respectivas aves de corral. Doña Práxedes aconseja a su comadre Doña Damiana deshacerse de su gallo. Desde el recuerdo, la buena mujer revive una situación semejante cuando una noche su gallo comenzó a cantar a deshora: «me despierto a eso de las dos en la cama, y oigo: quiquiriquí, quiquiriquí, que me entró un frío en la espalda que no me atrevía ni a moverme» (Jiménez 1988, 117). Doña Práxedes interpreta este canto como un mal presagio, la muerte de su hijo que está en el servicio militar, pero rápidamente cae en la cuenta de que lo anunciado es la muerte de Justo, el zapatero del pueblo: «pensé, enseguida: esto es que le ha pasado algo a mi Alberto, que estaba en el servicio militar, y se me caía el mundo encima; pero, luego, se me ocurrió en seguida que el Justo, el zapatero, estaba agonizando ya tres días en el pueblo y me dije: éste canta por él» (Jiménez 1988, 117-118).

Sin embargo, la desgracia está servida y contrita confiesa sentirse obligada a ajusticiar al animal. La perspectiva de cobijar a un gallo agorero se impone a su querencia y termina cortándole el pescuezo, «allí mismo en el corral, con el hacha de partir leña, se lo corté encima de un tocón de encina» (Jiménez 1988, 118). El círculo macabro se redondea cuando la señora revela que «en los días siguientes, me lo comí yo solita, sin decir nada a nadie» (Jiménez 1988, 118). La acción de matar, cocinar y comerse al gallo clandestinamente apunta a una utilización mágica del ave como apótrope. El sacrificio y posterior deglución silente del animal está muy cercana en apariencia a un ritual mágico/ supersticioso y otorga al gallo una función apotropaica dentro del cuento. Según Alvar Nuño, esta función se conjuga «con un principio habitual de la magia simpática, el de la oposición: se evita la muerte, haciendo alusión a ella» (2010, 
196). Con la muerte, se refirma la vida. Ese sería el significado del improvisado ritual que Doña Práxedes lleva a cabo en mitad de la noche ${ }^{12}$.

Ingrediente frecuente en las recetas mágicas, Molero señala como el gallo siempre ha estado muy presente en el ámbito de la magia, la nigromancia y la hechicería $(2014,3)$. Prueba de ello es que la devoración del ave agorera se completa con otro detalle crucial, también propio de las prácticas nigrománticas: la dueña todavía conserva algunas de las plumas del animal («Y las plumas todavía las guardo yo dos o tres en la cómoda envueltas en un papel fino de seda» [Jiménez 1988, 118]). Debatiéndose entre la nostalgia, la pena y el temor, esas plumas parecen actuar como amuleto contra los malos augurios. En síntesis, el gesto de doña Práxedes constituye un primitivo pero eficaz intento de alejar de sí y de los suyos la mala suerte. Con ello, el significado simbólico del ave en esta parte del relato se adentra en el terreno de la superstición y apunta, directamente, hacia una tradición de significado presidida por la magia y la hechicería. Algo común, por otra parte, en el área del Mediterráneo y de la Europa septentrional, en donde a las aves, según argumenta Roque, se les «otorga en el plano simbólico la capacidad de vaticinar, con su sola presencia, aspectos saludables o nefastos del futuro» $(2009,236)$.

A pesar de sus conocidas connotaciones positivas, el gallo queda retratado como un ave infernal. Se le considera una criatura perteneciente al mundo de los muertos y, por lo tanto, su presencia en el mundo de los vivos está cargada de fatalidad. Al cantar de noche, los términos se han invertido y lo bueno se ha convertido en malo o lo que es lo mismo, el gallo ha perdido su condición de ave benefactora para pasar a formar parte de las aves portadoras de desgracia. La imagen de la mujer comiendo secretamente el infausto gallo confiere un valor negativo al animal, un simbolismo ciertamente siniestro, y le adjudica un fuerte valor ctónico.

\section{MenSAJERO DE LOS DIOSES}

Criatura de mal agüero y emisaria de la muerte. Por ahora, esos parecen ser los principales significados que adopta el gallo. Sin embargo, ¿y si fuera el símbolo de la transición, del paso hacia una nueva aurora?

Así es como aparece perfilado el gallo en la segunda anécdota que compone este relato y de la que también es protagonista. Ya en el plano temporal del

${ }^{12}$ El ritual descrito de cocinar al gallo tiene grandes coincidencias con el pasaje de $E l$ satiricón ya citado, en el que después del canto del gallo, Trimalción decreta matarlo y cocinarlo con el fin de neutralizar sus posibles influjos nefastos: «En un abrir y cerrar de ojos se nos trajo al gallo de la vecindad y Trimalción mandó guisarlo en una cazuela. De modo que, troceado por aquel sabio cocinero que un poco antes había hecho pájaros y peces de carne de cerdo, fue metido en el puchero» (Petronio 1996, 166). 
presente de la narración, se relata el caso del ave de doña Damiana. Este parece revestir una mayor gravedad, ya que, de un tiempo a esta parte, su gallo ha adoptado la peligrosa costumbre «de que, en cuanto hay un muerto recién enterrado, se salta las tapias del camposanto a la mañana siguiente y se pone a cantar sobre la sepultura: quiquiriquí, quiquiriquí, tan contento como si fuera una fiesta» (Jiménez 1988, 119).

La situación es peliaguda y tiene numerosas implicaciones que podrían acarrearle a la dueña más de un problema. Las familias de los difuntos pueden sentirse molestas, en caso de considerar el canto como una burla hacia el finado. Cabe también la posibilidad de que otro vecino la acuse de amaestrar al animal contra los curas, «no te digo si tienes un malquerer y te lo mete por el Juzgado como cosa de Iglesia de que tú le has amaestrado» (Jiménez 1988, 119); anexa queda la cuestión de la suciedad que acompaña la macabra práctica del animalito, porque «icómo pone de echadas las sepulturas de mármol!» (Jiménez 1988, 120), concluye, taxativa, doña Práxedes.

En esta ocasión, lo significativo no es la hora a la que canta el gallo, sino el momento: «en cuanto hay un muerto recién enterrado». Los personajes interpretan así el canto del ave como una celebración de la muerte, de su victoria ineluctable sobre la vida. Pero ¿pudiera ser el «quiquiriquí» del gallo una llamada destinada al alma del muerto para ayudarla a llegar al más allá, en lugar del anuncio de un fallecimiento? En otras palabras, ¿hemos de considerar al gallo un guía hacia una vida nueva, en lugar de embajador de la muerte?

La hipótesis cobra sentido cuando nos centramos en la semántica mítica del animal, nos retrotraemos a su simbología más primitiva y fijamos nuestra atención sobre la riqueza de sus matices en el mundo pagano. En el panteón grecolatino el gallo se encuentra vinculado al dios Hermes o Mercurio, el celebérrimo mensajero de los dioses, y era uno de sus símbolos característicos. A este dios, Kerényi lo consideraba el conductor de almas, «aquel que no teme los peligros de lo más hondo de las profundidades ni los caminos más nuevos» $(2010,96)$ y, como tal, era el encargado de acompañar al Hades las almas de los difuntos, función que le valió el nombre de psicopompo (Grimal 1989, 262). En consecuencia, la escena del gallo encaramado a las lápidas y cantando a pleno pulmón que describe Doña Práxedes, bien puede entenderse como el acto de este emisario de los dioses alertando al alma del muerto para guiarla hacia la eterna aurora. El gallo pasaría entonces considerarse una «hierofanía», según la definición propuesta por Mircea Eliade $(1973,18)^{13}$. Sería la representación del dios Hermes cumpliendo su mitológica misión. Fenómeno frecuente, si

${ }^{13}$ El filósofo rumano define la «hierofanía» como el encuentro del hombre con una manifestación de lo sagrado: «El hombre entra en conocimiento de lo sagrado porque se manifiesta, porque se muestra como algo diferente por completo de lo profano Para denominar el acto de esa manifestación de lo sagrado hemos propuesto el término de hierofanía, que es cómodo, puesto que no implica ninguna precisión suplementaria: no expresa más que 
tenemos presente que «tanto las culturas mediterráneas como en las europeas septentrionales, las aves son mensajeros de los dioses» (Roque 2009, 236).

Aunque tradicionalmente esta tarea ha sido llevada a cabo por otros animales como el perro o el caballo ${ }^{14}$, que el gallo desempeñe este cometido tampoco resulta inusual. Desde antiguo, las imágenes de las aves se han vinculado con el alma humana y con el tránsito que recorre entre el cielo y la tierra, lo cual ha propiciado la actuación de las aves como mediadoras entre los dos mundos (Manrique 2016, 45). A caballo entre el día y la noche, entre el cielo y la tierra, a través de la vida y de la muerte, el gallo se perfila como el mediador excepcional entre el mundo de aquí y el de allí. Gracias a su biósfera liminal, el gallo se encuentra más que capacitado para conducir las almas hacia el Más Allá. Al igual que el dios al que representa, el ave juega el papel de psicopompo dentro del relato, puesto que con su escandalosa costumbre el animalito anuncia otro mundo, conducirá hasta allí el alma del difunto, de manera que así, «ésta abre los ojos a una nueva luz, lo que equivale a un nuevo nacimiento» (Chevalier y Gheerbrant 1986, 521).

De lo expuesto hasta el momento se advierte, primero, que el gallo se inscribe dentro de la tradición de significado de la mitología clásica, en tanto que su presencia puede interpretarse como una transfiguración del dios Mercurio. Segundo, que esta ave es una criatura antitética, vinculada por igual a la oscuridad y al reino de la muerte que a los dominios de la resurrección y el milagro cotidiano de la luz. De no ser así, cómo explicar el conocimiento que demuestra el animal de las tumbas recién estrenadas. ¿Por qué siempre va a cantar «precisamente en las tumbas recentitas que ¿en qué las conocerá?» (Jiménez 1988, 120), se interroga Doña Práxedes.

\section{CUANDO LO COTIDIANO SE HACE EXTRAORDINARIO}

Si hasta ahora habíamos situado los posibles significados del gallo dentro de los márgenes de la superstición y la mitología, en la última parte del texto las palabras de la narradora nos permiten adentrarnos en la vertiente espiritual de la simbología de este animal y atender a su significado religioso en la religión cristiana.

Cuando la mujeruca relata cómo el gallo «se empina y saca el pescuezo para cantar como si quisiese despertar a los muertos» (Jiménez 1988, 120), lo equipara con el «Ángel de la Trompeta del Juicio final, que es lo que parece

\footnotetext{
lo que está implícito en su contenido etimológico, es decir, que algo sagrado se nos muestra» (Eliade 1973, 18).

${ }^{14}$ El gallo figura entre los animales psicopompos ofrecidos tradicionalmente a los muertos en los ritos funerarios de los antiguos germanos. Para más información al respecto, ver Guerrero Ayuso y López Pardo 2006 y Gómez Casal 1998.
} 
el escuchimizado animal» (Jiménez 1988, 119). En este momento el canto del gallo resulta más que revelador, ya que abre el texto a la cuestión escatológica. La comparación entre la figura bíblica del séptimo ángel del libro del Apocalipsis y el gallo traslada la historia a un contexto muy preciso, el día del Juicio de Dios o Dies irae, momento en el que toda la humanidad será juzgada según sus obras.

Doña Práxedes dice que el gallo anda «haciendo de ángel trompetero en el camposanto» (Jiménez 1988, 120). O sea, que ya no está avisando a los muertos para que le sigan al mundo de ultratumba, sino que ahora al animal se le otorga un nuevo cometido: despertar a los muertos para que acudan a la llamada de Dios, como «ángel trompetero» que es, y sean juzgados por sus actos. Aunque la asimilación del gallo con la figura bíblica parece clara, resulta no ser así. El propio autor explica que la imagen no está tomada de la Biblia, sino de sus propios recuerdos:

Mi idea del Ángel del Juicio con la trompeta me llega no de la Biblia sino de la iconografía y cultura en la que todavía llegué a vivir, y estaba en la escuela y entre la gente. La imagen de los muertos levantándose al son de la trompeta de un ángel prolifera en la edad media y se puede ver sobre todo esculpida en atrios y capiteles ${ }^{15}$.

Inserto en este contexto escatológico el gallo alcanza su plenitud simbólica. Al designarlo como emisario del día del juicio final enlaza con varios de los significados que la religión católica le ha otorgado. Frente a la riqueza de matices provenientes del mundo pagano arriba mencionadas, «el cristianismo privilegió en su interpretación del animal ciertos sentidos simbólicos como los de vigilancia y superación del sueño de la muerte, tomando su canto como la fuerza que ahuyenta las tinieblas y el mal» (Macías 2012, 337). Junto con el león, el toro y el cordero, el gallo es uno de los emblemas de Cristo (Charbonneau-Lassay 1997, 633) y en él siempre se ha puesto particularmente de relieve su simbolismo solar. Asociado a ello, la aparición de su figura significa la llegada de la luz iniciática, la victoria sobre las tinieblas. Su canto evoca la resurrección de los muertos, el advenimiento de una vida y un mundo nuevos ${ }^{16}$. En el cuento es el animal elegido por Dios para proclamar el final de los tiempos y ello proyecta al animal hacia su función simbólica primigenia: la anunciación del nuevo día ${ }^{17}$.

15 Correo personal de Jiménez Lozano enviado el 11 de abril de 2018.

16 A este respecto es importante mencionar que entre los cristianos primitivos se representaban gallos en las tumbas y sepulcros como símbolo del día que estaba por venir tras la noche de la muerte, es decir, de la resurrección (Charbonneau-Lassay 1997, 638).

17 En este mismo contexto apocalíptico resulta oportuno mencionar otras cualidades atribuidas al gallo por la religión cristiana. Así, en Marcos 13,35, Jesús recomienda a los hombres estar atentos y siempre vigilantes (la vigilancia es una de las características 
Por otra parte, no ha de pasar desapercibida la ironía subyacente en este fenómeno de transformación del ángel en gallo, muy propio del autor. Nutriéndose de sus vivencias y recuerdos personales, Jiménez Lozano se decanta por la figura de un gallo como emisario de la voluntad divina. Animal doméstico, humilde y ordinario, propio de gentes menesterosas y que, además, se describe como un ave enclenque, «que no tiene un cuarto de libra de carne» (Jiménez 1988, 120). El autor deja de lado las grandiosas representaciones tradicionales de los ángeles apocalípticos y opta por representar al mensajero de Dios con una imagen familiar y sencilla, muy en consonancia con su forma de concebir la literatura ${ }^{18}$.

El retrato que el castellano nos presenta del Día del Juicio Final también concuerda con estos presupuestos estéticos: «qué más quisiera yo y tú y todos que lo del Valle del Josafat fuera que el canto de un gallo nos despertarse como de la cama y ¡hala! otra vez a tu casita y a vivir tan ricamente allí» (Jiménez 1988, 120). Lejos de fastos y grandes cataclismos, Jiménez Lozano imagina el momento casi como un acto cotidiano, de una manera sencilla y modesta, el habitual «despertarse de la cama».

Al ser interrogado por Guadalupe Arbona por esta curiosísima relación entre los gallos y el apocalíptico ángel de la trompeta, Jiménez Lozano refrenda esta concepción, cuando responde que hace alusión a que

El gallo anuncia el nuevo día, y Prudencio en sus himnos no duda en hacerle figura de Cristo llamándonos del sueño para despertar a la verdad, y en Shakespeare aparece como el que disipa los terrores de la noche. Y tiene Holan un precioso poema en su libro Una noche con Hamlet, que tradujo mi amigo Josef Forbelsky, en el que el alba de la resurrección de los cuerpos es una escena ca-

atribuidas al gallo), porque no se sabe cuándo llegará el señor de la casa. Juan en 1,9 habla de Jesucristo como la luz verdadera que al llegar al mundo iluminará al hombre. El gallo, en su papel de anunciador del día, sería simbólicamente el anunciador del nacimiento de Cristo.

${ }^{18}$ Es muy propio de la poética jimenezlozaniana recurrir a lo más pequeño y humilde para representar lo grandioso del hombre y de su existencia. En una conferencia impartida en la Residencia de Estudiantes, el autor lo ejemplificaba con la historia de Siphrah y Puah, contenida en el libro del Éxodo. Dos «jóvenes parteras que desobedecen la orden faraónica de matar a cada niño de sexo masculino que nazca entre los hebreos» (Jiménez 2003, 72). En su conjunto, la obra de José Jiménez Lozano se caracteriza por esta defensa del pequeño relato frente a los «Grandes Relatos» de la modernidad. Es una opción estética que comporta una ética o lo que es lo mismo, se trata de expresar mediante la estética de lo pequeño e insignificante contra lo majestuoso y faraónico, la de la hermosura de lo humano y de lo que significa vida contra lo que está construido y, aunque posea una cierta hermosura, es algo muerto. Y es la opción, en fin, por los oprimidos frente al opresor. Es decir, la opción ética que corresponde exactamente a la opción estética de contar la historia encantadora y justiciera de las dos comadronas que aseguran la vida de los recién nacidos mientras se guarda silencio sobre la «Gran Historia» de los faraones y su gloria (Jiménez 2005b, 173-174). 
sera en la que mamá, que se ha levantado la primera, enciende el fuego y muele el café para el desayuno; y, si el poema concluye afirmando que de nuevo estaríamos en casa, ¿no se oiría entonces al gallo cantando en el corral? No sería mal Ángel del Juicio Final un gallo (2011, 70-71).

Sin embargo, que ello no nos conduzca a error acerca de la importancia que Jiménez Lozano le otorga a esta circunstancia, ya que al autor le fascina verdaderamente el Día del Juicio Final y son varios los textos en los que ha quedado plasmado este interés ${ }^{19}$. En sus dietarios encontramos varias entradas que mencionan directamente esta cuestión. En una de ellas codifica ese momento con la imagen de un gran libro con las historias de todos los hombres y reflexiona sobre la oportunidad de acercarse para vislumbrar retazos de esas «historias de hombres» que tanto le fascinan.

El afán de algunos hombres en algunos tiempos ha sido el de hacer un libro donde esté todo: y eso, en cierto modo, fueron las Summas medievales, luego la Enciclopedia de la Ilustración, y, en nuestro tiempo, las grandes enciclopedias que, según nos dice la propaganda, nos traen todo el saber a casa. Todo resuelto, por lo visto; y mucho más con los ordenadores. Sin embargo, lo que a uno le gustaría leer de verdad es ese libro del que habla el Dies irae: un libro que se llevará al Juicio último y en el que realmente estarían todas las hermosas, trágicas, vergonzosas y sublimes aventuras humanas: Liber scriptus proferetur/ in quo totum continetur/ unde mundus iudicetur (Jiménez 1992, 18).

\section{El GALICINIO DE LA TRAICIÓN}

Pasemos ahora a analizar el cuento de «El Benefactor». Texto poliédrico, que rezuma nostalgia por la infancia y los sueños perdidos, está incluido en la colección El santo de mayo (1989). El relato narra la historia del dictador de una imaginaria república bananera que sufre prolongados periodos de lo que, en el cuento, se denominan como «ausencias». Así, «de repente, durante una conmemoración oficial o departiendo con sus consejeros de Estado, se veía como sus ojos azules vagaban muy lejos, en el interior de sí mismo y por un tiempo muy antiguo que debía de brotar allá dentro» (Jiménez 1989, 159).

19 En lo que a textos de creación se refiere, existen dos cuentos en los que el autor trata abiertamente la temática del Juicio Final. Uno de ellos es «La piel de los tomates» y da título a la colección de cuentos publicada en el año 2004. El otro se titula, precisamente, «El Juicio Final» y cuenta la historia de una abuela y su nieta que salen juntas a hacer un recado y mientras caminan por la calle ven un gentío adentrarse en un cine cuya proyección se titula «El Juicio Final». La joven acuerda con su madre encontrarse en una cafetería porque ese día corren noticias de que no se pondrá el sol (Jiménez 2004, 50-58). 
Prestemos atención a la expresión que el autor emplea para designar los recuerdos del personaje cuando nos dice «un tiempo muy antiguo». A través de ella, se advierte al lector del ejercicio de introspección que el personaje protagonista del relato lleva a cabo frecuentemente. Es importante, también, la puntualización de que ese tiempo brota de «allá dentro». Se trata de una imagen muy bella en donde se identifica el nacimiento de los recuerdos con un cauce de agua mediante el uso del verbo «brotar». Asimismo, se ubica ese caudal en los «adentros» de la persona, manifestando así la profundidad e importancia de aquello que se está rememorando. Posteriormente se identificará este «tiempo muy antiguo» con los recuerdos que el dictador guarda de la infancia, etapa de vital importancia para comprender el desenlace del cuento.

Con el tiempo descubren que el anciano sátrapa viaja a la selva en que nació, allá donde se encuentra «un gallo salvaje de plumas rojas y verdes que, desde el tejado de la cabaña donde nació, le reveló su destino de conductor de pueblos» (Jiménez 1989, 160-161). De nuevo, el gallo aparece como motivo principal del relato, aunque en esta ocasión va a mostrar su faceta oracular, dando a conocer al protagonista su destino.

Tanto babilonios, como romanos y árabes llevaban a cabo prácticas de alectomancia en relación con el movimiento del gallo (Molero 2014, 2). Pero sí es importante que debido a esta circunstancia el gallo va a convertirse en el animal totémico del dictador y los colores de sus plumas se adoptarán como los tonos oficiales del país. El rojo y el verde serán el

color de la bandera y de la banana que es su escudo, de los colores de la fachada de la Casa Presidencial y como la tinta de dos colores que se firman las sentencias, como la peluca de los jueces y el manto y la ropa interior del Benefactor, como los pendientes que lleva en sus orejas y las cintas que luce en la solapa ${ }^{20}$ (Jiménez 1989, 161).

${ }^{20}$ El escritor Donato Ndongo narra la dictadura de Francisco Macías sufrida en Guinea Ecuatorial durante los años de 1969-1979 a través del regreso de un hombre exiliado, abogado en Madrid, y que, junto a su mujer y su hija, vuelve a su tierra en un intento por contribuir al progreso de su país y ver a su familia y amigos de nuevo. Sin embargo, al llegar el protagonista sufrirá las brutales consecuencias del régimen dictatorial. Un régimen que, al igual que el del cuento de Jiménez Lozano, también tiene al gallo como animal simbólico, tal y como se muestra en este pasaje de la novela: «A pocos metros, un fornido miliciano con galones de cabo o sargento, no sé increpaba a un niño por llevar un gallo con la cabeza hacia abajo, no sabes que es un delito de subversión llevar de esta manera tan indecorosa al símbolo de la revolución de nuestro honorable y gran camarada papá Mesie me Nguema Biyogo Ñegue Ndong, a ver, quiénes son tus padres, de qué poblado eres, a dónde vas con ese gallo, tráelo aquí si no quieres más problemas» (Ndongo 2014). Constituiría un interesante estudio de literatura comparada llevar a cabo un análisis del significado del gallo como motivo simbólico de poder y degeneración moral en ambas obras literarias. 
De esta manera, el gallo se convierte, de nuevo, en el principal motivo simbólico del cuento, porque a través de su figura se canalizan muchas otras significaciones que están más allá de su presencia como animal en el relato del gallo. La acción narrativa alcanza su cenit en el momento de la coronación del tirano como «Benefactor de la Patria a los cincuenta años de progreso» (Jiménez 1989, 161). Ese día sufre una ausencia más larga de lo habitual y, harto ya de la espera, el más joven de los consejeros toma la decisión de buscar un gallo para hacer salir de su ensueño al autócrata. Cuando aparece en el salón, el animal salta sobre el trono del dictador y comienza «a cantar un aria de amanecer con la voz de los muertos y de los que se arrepentían en la cárcel y con la voz de su infancia sobre todo al oído de la majestad veneranda del Benefactor» (Jiménez 1989, 162).

El galicinio del gallo se disgrega y apunta hacia tres significados diferentes, marcados gramaticalmente por las dos conjunciones copulativas que articulan el enunciado. Por un lado, el gallo canta «con la voz de los muertos», es decir, canta con la voz de las víctimas. Su canto lo conforma el clamor de los que pueblan los cementerios y las fosas comunes. Todos ellos van a revivir -nótese que, de nuevo, se ensalza al gallo como símbolo de la resurrección- con el canto del gallo para susurrarle al dictador su ignominia y su cobardía. Pero el gallo canta también «con la voz de su infancia» y su canto retrotrae al dictador a la niñez, a ese «tiempo muy antiguo que brota de los adentros», antes señalado, lo cual convoca ante el protagonista una constelación de recuerdos felices. Recuerdos a los que el hombre ha de mantenerse fiel con el fin de salvaguardar su humanidad.

En este sentido, la relación entre el gallo como símbolo de la infancia y el dictador podría establecerse según los parámetros planteados por Jung cuando trata el tema de la independencia del hijo respecto de la figura materna. Aunque la persona lleve a cabo el desarrollo total de la conciencia y se produzca la separación de los progenitores, dice Jung que «el anhelo por ese mundo perdido subsiste, y cada vez que la adaptación se vuelve dificultosa, induce a evasivas y retrocesos, a regresar a la primitiva época infantil» $(1998,249)$. De manera que el canto del gallo para el protagonista del relato adquiere un significado de nostalgia y de pérdida por ese tiempo remoto y cuasi-olvidado al que se ansía regresar.

Por otra parte, el valor concedido a la infancia y a sus recuerdos en este plano del relato también se explica, en parte, por la devoción que Jiménez Lozano siempre ha mostrado hacia esta etapa de la vida. Para el castellano la infancia reviste una importancia capital y cuando Gurutze Galparsoro le pregunta en Una estancia holandesa si la infancia constituye la auténtica patria del hombre y del escritor, Jiménez Lozano responde, junto con Rilke, que sí y redondea la certeza: «el resto de la vida es un exilio. Bernanos decía que la infancia nos sostiene también a la hora de la muerte. En realidad, su recuerdo de verdadera patria nos acoge siempre» (Jiménez y Galparsoro 1998, 79). 
Quizá el tirano no imaginó su misión salvífica en los términos de brutalidad y sometimiento descritos en el texto. Posiblemente vislumbró un destino muy diferente al que ahora tiene ante sus ojos, pero el poder y sus corruptelas acabaron arrastrándole al abismo de la putrefacción moral. «Te has traicionado a ti mismo», parece cantarle el gallo al dictador. Y en ese recordatorio de la traición en forma de canto resuenan, inevitables, los ecos del gallo evangélico que cumplió el vaticinio de Jesús y cantó después de que Pedro negase a su maestro. Estas resonancias apuntan directamente a uno de los significados primordiales del gallo: la vigilancia, mencionada por Juan Eduardo Cirlot en su Diccionario de símbolos $(2011,219)$, afín al valor simbólico de advertencia al pecador que tiene el gallo en el mundo cristiano.

La cuestión es que, para bien y para mal, el canto del gallo despierta al mandatario de su pesadilla, erigiéndolo, de nuevo, como un símbolo de renacimiento, como antes ya apuntamos. Así, «antes de nadie pudiera reaccionar, el dictador se había despojado de su uniforme y su corona, y, con un brazo poderoso, ahogaba al gallo» (Jiménez 1989, 162-163). Por ese galicinio el dictador renace a su forma natural y responde en consonancia con ella, de una forma bárbara y brutal, ante el sonido de su derrota aquilatada en el canto argénteo del ave anunciadora.

Este mismo canto será el que introduzca el relato en el terreno de lo fantástico y su sonido propicie la transformación de los cortesanos en distintas clases de pájaros

los consejeros se convertían en papagayos o cacatúas con su moño pintado y otros funcionarios en urracas y el chambelán-obispo en un búho con gafas de présbita y un cortesano en un águila, y las mujeres en correcaminos y torcaces murmuradoras, y el pueblo todo en pequeños gorriones pardos ateridos de frío (Jiménez 1989, 163).

El ave de la mañana obra la maravilla y desvela la idiosincrasia animal de todos aquellos disfrazados de hombres. Su canto valiente desenmascara también con su poder al sátrapa. Revela su naturaleza simiesca, mostrándolo metamorfoseado «en un mono o siempre había sido un mono, que aullaba de miedo y de venganza [...] encaramado ahora en las ramas más altas que devoraba al gallo ansiosamente» (Jiménez 1989, 163). Sí, el mono se come al gallo. Una vez más, el ave es sacrificada en aras de la verdad. Su sino como oráculo $\mathrm{y}$ anunciador parece estar sellado también en este cuento. Al igual que doña Práxedes se comió a su gallo por cantarín y agorero en el cuento anterior, en «El Benefactor» también el ave es víctima de un destino aciago: muerte y posterior deglución.

¿Posible uso apotropaico del ave? No parece apuntar el texto en ese sentido. La reacción del simio se inclina, más bien, hacia la venganza y la ira. El «Benefactor-tití» (Jiménez 1989, 163) se cobra en las carnes del gallo parte de la venganza que no puede ejercer contra sí mismo tras constatar el fracaso de 
su legado. La rabia y la frustración sentidas por el mono le impulsarán a destruir a ese animal convertido en el Alfa y el Omega de su existencia. El canto del gallo le desveló su destino y el canto del gallo marcará su ocaso y su fracaso. El círculo sombrío se cierra también así en este relato.

Aunque puede parecer que el cuento termina con la muerte del animal, aún quedan cuentas pendientes. El mono exdictador guarda en la manga una última carta con la que ejercer y demostrar su poder omnímodo, a la vez que redondear su represalia contra el gallo insolente. La otra parte de su desquite la reserva para el resto de los congéneres del ave. Todo su temor y su furia se tornarán en felicidad cuando decrete «la extinción urgente y absoluta de los gallos, cantarines, deslenguados, reveladores, cualquiera que fuese, por lo demás, el color de sus plumas» (Jiménez 1989, 164). Medida desmesurada, pero superada con creces por otra aún mayor y propia de todo dictador que se precie: la «censura estricta de los peligrosos sueños de la infancia, que ellos evocan con su canto» (Jiménez 1989, 164).

Prohibido soñar o, lo que es lo mismo, prohibido vivir. El hombre es hombre por lo que reza, por lo que teme y por lo que sueña y arrebatada esta última facultad, arrebatada también parte de su alma, lo cual garantiza la supervivencia de una estirpe de sujetos alienados, incapacitados para soñar y destinados únicamente a vivir para perpetuar el culto al líder.

En suma, el canto del ave pasa a representar la destrucción de la belleza impoluta de los sueños infantiles, pero también la pérdida del sentido de la identidad del individuo. Cantando al oído del dictador el gallo reivindica el poder restaurador de la memoria y le recuerda el siempre traicionero paso del tiempo. Se trata de imágenes de una belleza malograda por el reloj y despedazada por la catástrofe, cuyo resultado final es el fatal retrato de aquello en lo que se ha convertido el glorioso Benefactor: una bestia gruñidora carcomida por el poder, el miedo y el odio.

\section{Conclusiones}

Ave de mal agüero, oráculo del futuro, psicopompo de los dioses, emisario del juicio final, denunciador de la traición y recordatorio de los sueños traicionados. El gallo adquiere todos estos perfiles en los relatos analizados y acogiendo bajo sus alas todas estas significaciones prueba su versatilidad como motivo simbólico. Una versatilidad que José Jiménez Lozano ha sabido aprovechar para crear dos historias soberbias, repletas de refracciones y que apuntan en muy distintas direcciones. Mitología y superstición, religión y magia, simbología y fantasía se entremezclan en las páginas comentadas para ofrecer al lector un universo y una mirada únicos sobre el mundo.

«El ángel del Juicio» reconcilia los aparentemente contradictorios aspectos simbólicos y ancestrales del gallo, ofreciendo una imagen polifacética y hete- 
rogénea del animal. En sus páginas, el ave es sometida a un proceso de resemantización muy complejo, en el que se anudan la vertiente supersticiosa y pagana del símbolo con la faceta mítica y religiosa. Gracias al gallo se desvela la dialéctica basada en la ley de los contrarios sobre la que el autor ha construido este cuento. «De la vida sale la muerte y de la muerte, la vida», parece venir a decirnos. Además, que el gallo cante durante la noche, y no a la salida del Sol, subraya la importante correlación entre muertos/ vivos y noche/ día que atraviesa todo el texto y le otorga una profundidad antropológica y simbólica trascendentales.

En «El Benefactor» el gallo es el motivo simbólico más importante del relato. Su ascendiente sobre el personaje es tan poderoso que desata la acción principal del cuento y lo aboca a una metamorfosis tan merecida como desconcertante. La aparición del gallo propicia, por un lado, el desvelamiento del destino del sátrapa, mientras que su canto, por otro, denuncia la traición perpetrada por el dictador a los sueños de la infancia. Emblema del país, como también lo es del destino incumplido y de las esperanzas e ilusiones destruidas.

$\mathrm{El}$ análisis realizado de los cuentos «El ángel del Juicio» $\mathrm{y}$ «El Benefactor» muestra la elasticidad del gallo para conjugar un amplio haz de significaciones. $\mathrm{Si}$ atendemos a las funciones desempañadas por el motivo del gallo en los textos, esta afirmación encuentra su justa corroboración. En el primero cumple tres funciones pobladas de paradojas, tales como la de ser a un mismo tiempo presagiador de lo inevitable, mensajero de una voluntad superior y mediador en términos espirituales. En el segundo cuento desempeña una función de denuncia de la barbarie y de defensa de las víctimas aplastadas por el régimen dictatorial, a la vez que actúa como albacea de la memoria del viejo sátrapa al recordarle su destino malogrado.

Por lo tanto, teniendo en cuenta la heterogeneidad de significados y funciones señalados, toma carta de naturaleza la consideración del gallo como un melting-pot simbólico. Un símbolo en constante evolución y siempre cambiante, en virtud de lo cual se le han ido añadiendo, superponiendo y mezclando significaciones de muy distinta naturaleza, algunas de ellas contradictorios, pues «la evolución de una forma simbólica presenta en sus aspectos profundos una bipolaridad de aspectos llamativa, que queda encadenada, por decir, en la estructura del símbolo» (Aladro 2010, 134). En nuestro caso concreto, el resultado es una mixtura híbrida y compleja que hacen del ave un símbolo animalístico muy poderoso.

\section{FUENTES}

Jiménez Lozano, José. 1988. El grano de maíz rojo. Barcelona: Anthropos. Jiménez Lozano, José. 1989. El santo de mayo. Barcelona: Destino. Jiménez Lozano, José. 1992. Segundo abecedario. Barcelona: Anthropos. 
Jiménez Lozano, José. 2003. El narrador y sus historias. Madrid: Publicaciones de la Residencia de Estudiantes.

Jiménez Lozano, José. 2004. La piel de los tomates. Madrid: Ediciones Encuentro.

Jiménez Lozano, José. 2005a. Antología de cuentos. Madrid: Cátedra.

Jiménez Lozano, José. 2005b. «Apuntes y soledades». En Naturalezas del escribidor. Ofrenda de amigos a José Jiménez Lozano, ed. Alfredo Pérez Alencart y Antonio Colinas. Salamanca: Trilce.

Jiménez Lozano, José. 2006. Advenimientos. Valencia: Editorial Pre-Textos.

Jiménez Lozano, José. 2017. Buscando un amo y otras aprensiones. Madrid: Rialp.

Jiménez Lozano, José y Gurutze Galparsoro. 1998. Una estancia holandesa. Conversación. Barcelona: Anthropos.

Petronio. 1996. Satiricón. Madrid: Akal.

Shakespeare, William. 2006. Hamlet. Madrid: Cátedra.

\section{BIBLIOGRAFÍA CITADA}

Aladro Vico, Eva. 2010. «La estructura de los símbolos». Perspectivas de la Comunicación 3 (2): 134-147.

Alvar Nuño, Antón. 2010. «Nocturnae aves: su simbolismo religioso y función mágica en el mundo romano». Arys. Antigüedad: Religiones y Sociedades 8: 187-202.

Arbona, Guadalupe. 2008. El acontecimiento como categoría del cuento. Madrid: Arco Libros.

Arbona, Guadalupe. 2011. Las llagas y los colores del mundo. Conversaciones literarias con José Jiménez Lozano. Madrid: Ediciones Encuentro.

Arbona, Guadalupe. 2016. «La infancia de José Jiménez Lozano. La casa, la escuela, los primeros trayectos». En De Ávila a Constantinopla: los viajes fabulosos de José Jiménez Lozano, ed. Guadalupe Arbona, Antonio Martínez Illán, Anna Fomicheva (Kovrova) y Victoria Howell, 17-110. Ávila: Institución Gran Duque de Alba.

Beristáin, Helena. 1995. Diccionario de retórica y poética. Porrúa: México.

Castro Pérez, Ladislado y Manuel García Valdeiras. 1997. «El simbolismo del gallo en el noroeste peninsular, de la protohistoria a la tradición Jacobea». Minius: Revista do Departamento de Historia, Arte e Xeografia 6: 29-40.

Charbonneau-Lassay, Louis. 1997. El bestiario de Cristo. El simbolismo animal en la Antigüedad y la Edad Media. 2 vols. Palma de Mallorca: Sophia Perennis.

Chevalier, Jean y Alain Gheerbrant. 1986. Diccionario de los símbolos. Herder: Barcelona.

Cirlot, Juan Eduardo. 2011. Diccionario de símbolos. Madrid: Siruela.

Ducrot, Oswald y Tzvetan Todorov. 1974. Diccionario enciclopédico de las ciencias del lenguaje. Buenos Aires: Siglo XXI Editores.

Eliade, Mircea. 1973. Lo sagrado y lo profano. Guadarrama: Madrid.

Estébanez Calderón, Demetrio. 1996. Diccionario de términos literarios. Alianza: Madrid.

Gómez Casal, Luis. 1998. «El caballo como animal psicopompo en la Grecia micénica». Gallaecia 17: 399-424.

Grimal, Pierre. 1989. Diccionario de mitología griega y romana. Buenos Aires: Paidós.

Guerrero Ayuso, Víctor M. y Fernando López Pardo. 2006. «Gallos en la cámara de la muerte, aproximación a su significado en la necrópolis de la Edad de Hierro, Cometa dels Morts (Escorca, Mallorca)». Mayurqa: Revista del Departament de Ciències Històriques i Teoria de les Arts 31: 211-229. 
Jung, Carl Gustav. 1998. Símbolos de transformación. Barcelona: Paidós.

Jung, Carl Gustav. 2002. Misterium Coniunctionis. Madrid: Trotta.

Kerényi, Karl. 2010. Hermes, el conductor de almas. Madrid: Editorial Sexto Piso.

Macías, Cristóbal. 2012. «El simbolismo del gallo en la obra de Picasso». Ágora. Estudios Clássicos em Debate 14: 325-350.

Manrique Granados, Ricardo. 2016. «Aves y literatura. El vuelo de las aves por la literatura». Boletín Cultural y bibliográfico 50 (91): 45-60.

Marchese, Angelo y Joaquín Forradellas. 2013. Diccionario de retórica, crítica y terminología literaria. Barcelona: Ariel.

Martínez Martínez, Ana María. 2019. El imaginario antropológico de Maestro Huidobro de José Jiménez Lozano. Tesis doctoral. Universidad Autónoma de Madrid. https:// repositorio.uam.es/handle/10486/660390

Molero, Antonio. 2014. «El gallo y la superstición». Gibralfaro. Revista de Creación Literaria y Humanidades 84 . http://www.gibralfaro.uma.es/leyendas/pag_1924.htm

Ndongo, Donato. 2014. Los poderes de la tempestad. Selección de fragmentos. Edición Natalia Álvarez Méndez. Alicante: Biblioteca Virtual Miguel de Cervantes. http://www.cervantesvirtual.com/nd/ark:/59851/bmctt6h5

Park, Stuart S. 2009. Las hijas del canto. Valladolid: Ediciones Camino viejo.

Ricoeur, Paul. 2006. Teoría de la interpretación. Discurso y excedente de sentido. Madrid: Siglo XXI editores.

Roque Alonso, Maria Angels. 2009. «Las aves, metáfora del alma». Quaderns de la Mediterrània $=$ Cuadernos del Mediterráneo 12: 236-244.

Steiner, George. 2001. Pasión intacta. Madrid: Siruela.

Tomachevsky, Boris. 1982. Teoría de la literatura. Madrid: Akal.

Fecha de recepción: 12 de noviembre de 2018.

Fecha de aceptación: 22 de marzo de 2019. 
